\title{
1,2-Dicarbonyl Radicals with Exceptional Physiological and Chemical Stability
}

Youngsuk Kim, Jung Eun Byeon, Gu Yoon Jeong, Seoung Su Kim, Hayoung Song, Eunsung Lee*

Department of Chemistry, Pohang University of Science and Technology (POSTECH), Pohang, 37673, Republic of Korea

\begin{abstract}
Organic radicals have been of great academic interest due to their unique reactivity and potential applicability; however, lack of stability and solubility continues to limit their application, especially in physiological conditions. For example, well-known aminoxyl radicals have half-life of a few minutes in physiological conditions due to biological redox active reagents, while shielding using polymeric or supramolecular protecting groups increases their half-life up to several hours. Here we designed and synthesized a new small molecular organic radical based on 1,2-dicarbonyl scaffold with exceptional stability. The presented radicals showed superior stability over present organic radicals towards physiological conditions (half-life of $\sim 3000$ hours) and even resistant towards chemically reducing, oxidizing, acidic, basic conditions, and high temperature, without additional protection.
\end{abstract}

Having an unpaired valence electron, organic radicals are often thermodynamically and kinetically unstable, making their isolation and structural characterization challenging. Since the 'radical' discovery of the triphenylmethyl radical - the first persistent organic radical - by Gomberg in $1900,{ }^{1}$ various strategies to stabilize organic radicals have been developed, leading to the successful discovery of other stable organic radicals (Figure 1A). ${ }^{2}$ Despite the great potential of air-and water-stable organic radicals as electron transfer reagents, spin labels, or bio-imaging agents, they have limited stability under physiological conditions, which makes a major drawback for bio-application. ${ }^{3}$ For example, the most widely studied aminoxyl radicals (also known as nitroxyl radicals) are susceptible to decomposition in the presence of organic or biological reducing agents such as ascorbate, while triarylmethyl radicals readily react with oxidants such as peroxides. ${ }^{4}$ Therefore, development of new organic radical platform is desired with high stability towards physiological conditions.

A<smiles>c1ccc([C](c2ccccc2)c2ccccc2)cc1</smiles>

Triarylmethyl<smiles>[R]C1CC(C)(C)N([O])C(C)(C)C1</smiles>

Aminoxyl

B

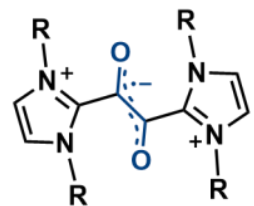

This work
Air \& water stable Physiologically stable

Acid \& base stable

Redox stable

Thermally stable

Figure 1. Examples of stable organic radicals.

(A) State of the art examples of most widely used organic radicals.

(B) Stable 1,2-dicarbonyl radicals from this work with the glyoxal radical anion core structure.

$\pi$-Conjugation enables the delocalization of spin density and hence increases radical stability. ${ }^{5}$ For example, glyoxal derivatives, as one of the simplest $\pi$-conjugated molecules, have been reported to generate corresponding 1,2-dicarbonyl radical anions, ${ }^{6}$ which are well-known redox active ligands. Several metal complexes containing 1,2-dicarbonyl radical anions have been reported; ${ }^{7}$ however, free 1,2-dicarbonyl radical anions are unstable, and have only been studied by spectroscopic and computational methods. For example, one electron reduction of phenylglyoxal derivatives produced the corresponding 1,2dicarbonyl radical anions which were detected by electron paramagnetic resonance (EPR). ${ }^{6}$ Nonetheless, we assumed that, with appropriate steric and electronic stabilization, 1,2-dicarbonyl can be a versatile organic radical fragment.

$\mathrm{N}$-heterocyclic carbenes $(\mathrm{NHCs})^{8}$ are well known to facilitate the generation and utilization of unstable species, ${ }^{9}$ including main group ${ }^{10}$ and organic radicals, including carbonyl, ${ }^{11}$ propargyl, ${ }^{12}$ and aminyl ${ }^{13}$ derivatives, for example. in this context, we designed 1,2-dicarbonyl radical supported by two NHCs which may provide steric protection and delocalization of the spin density (Figure 1B). 
Herein we report the synthesis and characterization of highly stable 1,2-dicarbonyl radicals with two imidazolium substituents. The presented radical has two major advantages over the widely used nitroxyl radicals: (i) it survives in the physiological reducing conditions while nitroxyl radicals rapidly decomposed to hydroxylamines, (ii) it has negligible spin density on the nitrogen and hydrogen atoms which results in a narrower EPR signal - and enables higher signal to noise ratio - compared to nitroxyl radicals. High stability and water solubility enabled the demonstration of those radicals as potential organic radical contrast agent candidates for magnetic resonance imaging.

\section{Results and discussion}

The 1,2-dicarbonyl radicals $\mathbf{2} \mathrm{a}^{\bullet+}$ and $\mathbf{2} \mathbf{b}^{\bullet+}$ can be easily synthesized from oxalyl chloride and the corresponding $\mathrm{N}$-heterocyclic carbenes (NHCs) (Figure 2A). Under a $\mathrm{N}_{2}$ atmosphere, the reaction of NHC 1a (IMes; 1,3-dimesitylimidazol-2-ylidene) or 1b (IDipp;

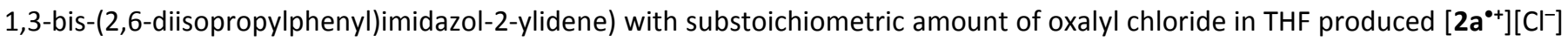
or $\left[\mathbf{2 b}^{\mathbf{}}\right]\left[\mathrm{Cl}^{-}\right]$, and subsequent anion exchange afforded $\left[\mathbf{2 a}^{\bullet+}\right]\left[\mathrm{BF}_{4}^{-}\right]$or $\left[\mathbf{2 b}^{\bullet+}\right]\left[\mathrm{BF}_{4}^{-}\right]$, respectively, as deep purple solids. The reaction involves the formation of the dication intermediate $\left[\mathrm{2a}^{2+}\right]\left[\mathrm{Cl}^{-}\right]_{2}$, followed by a spontaneous one electron reduction $($ See Supplementary Materials for detail).

A

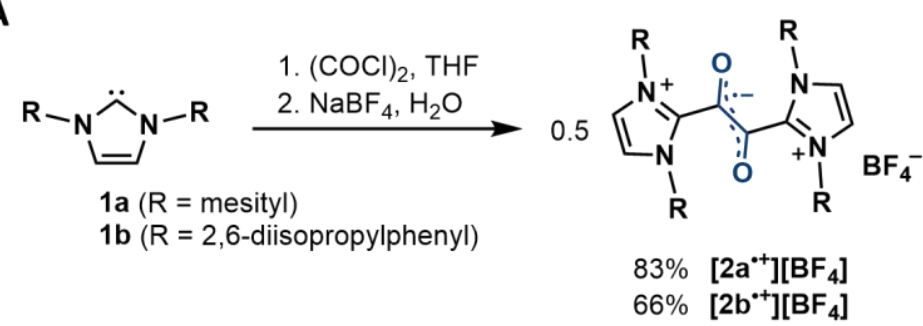

B
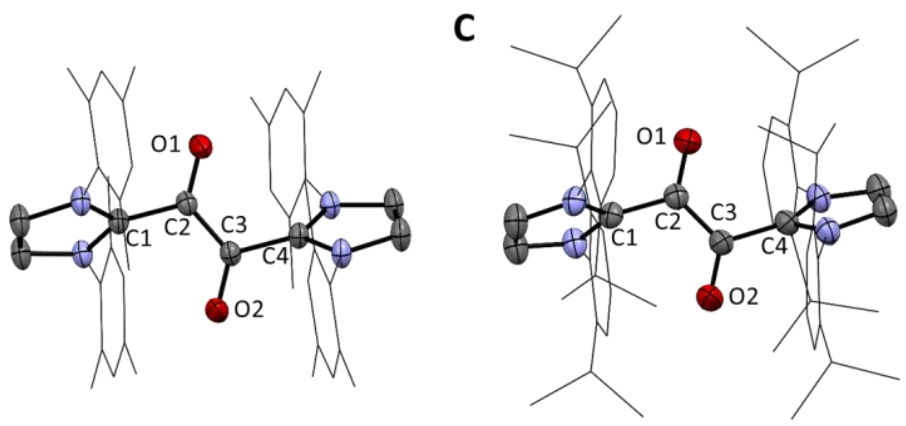

D

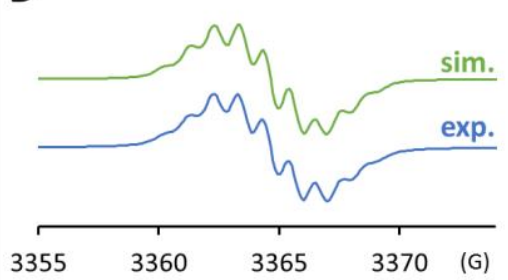

E

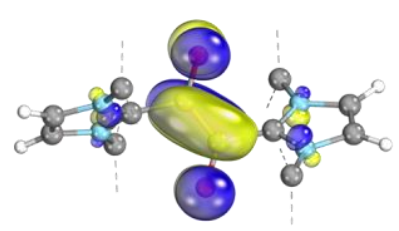

Figure 2. Synthesis and characterization of 1,2-dicarbonyl radicals.

(A) Synthesis of $\left[\mathbf{2 a}^{\bullet+}\right]\left[\mathrm{BF}_{4}^{-}\right]$and $\left[\mathbf{2}^{\bullet++}\right]\left[\mathrm{BF}_{4}^{-}\right]$from NHCs and oxalyl chloride.

$(B$ and $C)$ Solid-state structure of $(B)\left[\mathbf{2 a}^{*+}\right]\left[\mathrm{BF}_{4}^{-}\right]$and $(C)\left[\mathbf{2 b}^{\bullet+}\right]\left[\mathrm{BF}_{4}^{-}\right]$from single crystal X-ray crystallography. The thermal ellipsoids are shown at the $30 \%$ probability level. Anions, hydrogen atoms, solvent molecules and disorders were omitted for clarity.

(D) Experimental (bottom) and simulated (top) EPR spectra of $\left[\mathbf{2 a}^{\circ+}\right]\left[\mathrm{BF}_{4}^{-}\right]\left(\mathrm{g}=2.0060\right.$; hyperfine coupling constants: $a\left({ }^{14} \mathrm{~N}\right)=3.0,3.0,2.6,2.6$ $\mathrm{MHz})$.

(E) DFT calculated $\mathrm{SOMO}(\alpha)$ of $2 \mathrm{a}^{\bullet+}$ (M06/Def2-SV(P); mesityl substituents were omitted for clarity.

Single crystals suitable for X-ray crystallography were grown by slowly evaporating the mixed water/acetone solutions,

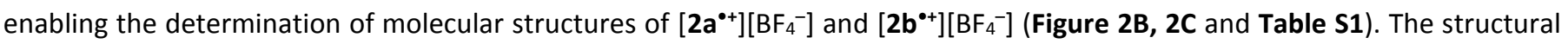
parameters for $\left[\mathbf{2 a}^{\bullet+}\right]\left[\mathrm{BF}_{4}^{-}\right]$and $\left[\mathbf{2}^{\mathbf{0}}\right]\left[\mathrm{BF}_{4}^{-}\right]$are almost identical and well reproduced with DFT calculation on M06/Def2-SV(P) 
level of theory (Table S2). The bond lengths of the central $\mathrm{C}_{2} \mathrm{O}_{2}$ unit indicate a bond order of 1.5 (O1-C2 1.245(2) $\AA$; $\mathrm{C} 2-\mathrm{C} 3$ $1.411(4) \AA ;$ C3-O2 1.245(2) $\AA$ for $\left.\left[2 \mathrm{a}^{\bullet+}\right]\left[\mathrm{BF}_{4}^{-}\right]\right)$. The planar structure of the central $\mathrm{C}_{2} \mathrm{O}_{2}$ unit also suggests $\pi$-delocalization of the radical (torsion angle for $\mathrm{O} 1-\mathrm{C} 2-\mathrm{C} 3-\mathrm{O} 2: 172.8(3)^{\circ}$ for $\left[\mathbf{2 a}^{\circ+}\right]\left[\mathrm{BF}_{4}^{-}\right]$). The Wiberg bond orders were calculated, which were

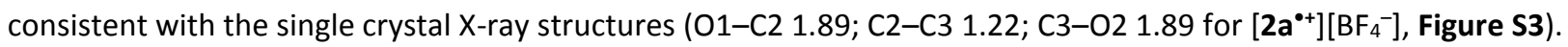

Typically, NHC derived radicals ${ }^{14}$ have delocalized spin density due to strong $\pi$ accepting ability of NHCs. ${ }^{15}$ In contrast, DFT calculations suggest that $\mathbf{2} \mathbf{a}^{\bullet+}$ and $\mathbf{2} \mathbf{b}^{\bullet++}$ are very rare examples of $\mathrm{NHC}$-derived radicals with minimal delocalization of spin density over the NHC fragments. Very interestingly, $98 \%$ of spin density of $2 a^{\circ+}$ is localized on the central $\mathrm{C}_{2} \mathrm{O}_{2}$ unit $(\mathrm{O} 132 \% ; \mathrm{C} 217 \%$; $\mathrm{C} 3$

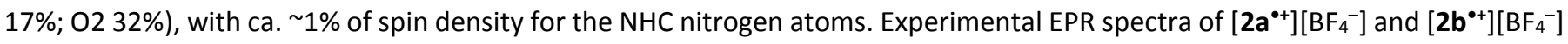
were nearly identical, and successfully simulated with hyperfine coupling from four nitrogen atoms with small coupling constants $\left(a\left({ }^{14} \mathrm{~N}\right)=3.0,3.0,2.6,2.6 \mathrm{MHz}\right.$ for $\left.\left[\mathbf{2 a}^{\circ+}\right]\left[\mathrm{BF}_{4}^{-}\right]\right)$, in agreement with the small spin density on the nitrogen atoms (Figure 2D). DFT calculated singly occupied molecular orbital (SOMO) of $\mathbf{2} \mathrm{a}^{\bullet+}$ (Figure $\mathbf{2 E}$ ) well reproduced the typical $\Psi_{3}$ orbital of a conjugated system with four $p$ orbitals (e.g. 1,3-butadiene). The UV-vis absorption spectrum of $\left[\mathbf{2 a}^{\bullet+}\right]\left[\mathrm{Cl}^{-}\right]$in distilled water at room temperature showed a peak at $\lambda_{\max }=472 \mathrm{~nm}$ which was well approximated by time-dependent DFT calculation at M06/Def2$\mathrm{SV}(\mathrm{P})$ level of theory (calculated $\lambda_{\max }=461 \mathrm{~nm}$ corresponding to $\mathrm{SOMO}(\alpha)$ to $\operatorname{LUMO}(\alpha)$ transition, Figure S10). Interestingly, $\left[2 \mathrm{a}^{\cdot+}\right]\left[\mathrm{Cl}^{-}\right]$shows weak solvatochromism as its absorption was red-shifted in organic solvents $\left(\lambda_{\max }=510 \mathrm{~nm}\right.$ in acetonitrile; $\lambda_{\max }$ $=521 \mathrm{~nm}$ in dichloromethane, Figure S11).

The cyclic voltammograms of $\left[\mathbf{2 a}^{\bullet+}\right]\left[\mathrm{BF}_{4}^{-}\right]$and $\left[\mathbf{2}^{\mathbf{0}}\right]\left[\mathrm{BF}_{4}^{-}\right]$were measured in acetonitrile, which showed reversible redox peaks at $E_{1 / 2}=0.516$ and $0.490 \mathrm{~V}$, respectively (vs. saturated $\mathrm{Ag} / \mathrm{AgCl}$ electrode, Figure $\mathbf{3 B}$ and Figure S6). Chemical oxidation of

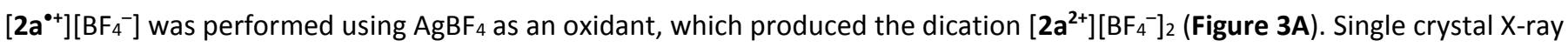
structure of $\left[2^{2+}\right]\left[\mathrm{BF}_{4}^{-}\right]_{2}$ (Figure $3 \mathrm{C}$ ) showed shortened 01-C2 (1.191(2) $\AA$ ) and C3-O2 (1.201(2) $\AA$ ), and elongated C2-C3 $(1.536(5) \AA)$ bonds, compared to $\left[2^{-{ }^{*+}}\right]\left[\mathrm{BF}_{4}^{-}\right]$. This can be rationalized by considering the removal of the unpaired electron from the $\Psi_{3}$ shape SOMO that enhances the bonding $\mathrm{O} 1-\mathrm{C} 2, \mathrm{C} 3-\mathrm{O} 2$ and antibonding $\mathrm{C} 2-\mathrm{C} 3$ interactions. In addition, torsion angle for $01-\mathrm{C} 2-\mathrm{C} 3-\mathrm{O} 2$ was significantly reduced to $156.9(4)^{\circ}$ (compared to $172.8(3)^{\circ}$ for $\left[2^{\circ{ }^{*+}}\right]\left[\mathrm{BF}_{4}{ }^{-}\right]$), which also indicates the decrease of $\mathrm{C} 2-\mathrm{C} 3 \pi$ bonding interaction. Calculated Wiberg bond indices of $2 \mathrm{a}^{2+}$ also showed increased bond order for $01-\mathrm{C} 2$ (2.27), C3-O2 (2.29), and decreased bond order for C2-C3 (0.97) compared to 2a*+ (Figure S3). On the other hand, electrochemical or chemical reduction of $2 \mathrm{a}^{\bullet++}$ and $\mathbf{2} \mathbf{b}^{\bullet++}$ to the corresponding neutral compounds was not successful.

A

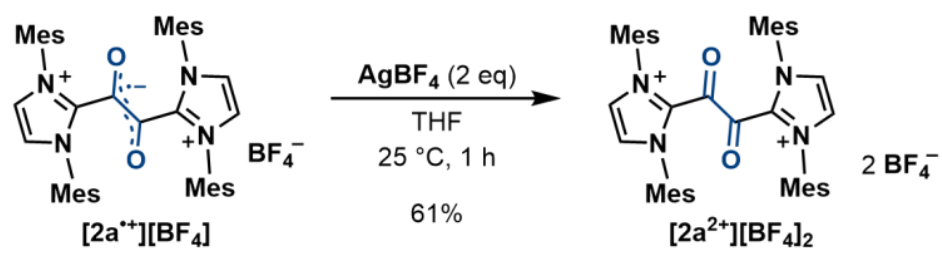

B

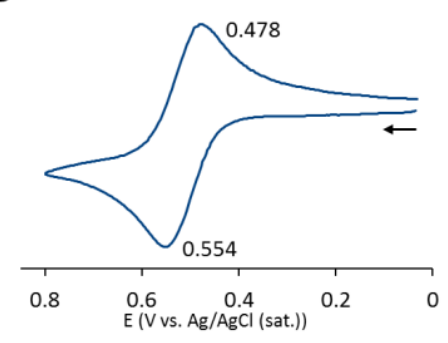

C

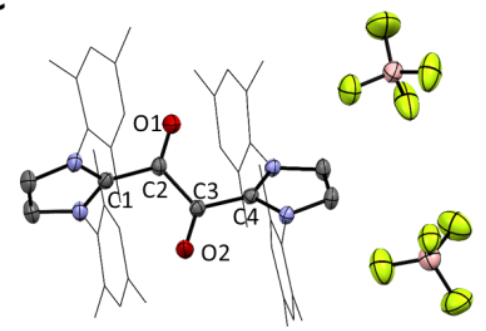

Figure 3. Redox behavior of the 1,2-dicarbonyl radical.

(A) One electron oxidation of $\left[2 \mathrm{a}^{\bullet+}\right]\left[\mathrm{BF}_{4}^{-}\right]$using silver tetrafluoroborate to produce $\left[2 \mathrm{a}^{2+}\right]\left[\mathrm{BF}_{4}^{-}\right]_{2}$.

(B) Cyclic voltammogram of $\left[2^{\circ}{ }^{\circ+}\right]\left[\mathrm{BF}_{4}^{-}\right]$in acetonitrile with $\mathrm{Bu}_{4} \mathrm{NPF}_{6}(0.1 \mathrm{M})$ as the supporting electrolyte (scan rate $=0.1 \mathrm{~V} / \mathrm{s}$ ).

(C) Solid-state structure of $\left[\mathbf{2 a}^{2+}\right]\left[\mathrm{BF}_{4}{ }^{-}\right]_{2}$ from single crystal X-ray crystallography. The thermal ellipsoids are shown at the $30 \%$ probability level. Hydrogen atoms, solvent molecules and disorders were omitted for clarity. 
To test the stability of 1,2-dicarbonyl radicals under physiological conditions, UV-vis spectrum of $\left[2 \mathrm{a}^{\bullet+}\right]\left[\mathrm{Cl}^{-}\right]$solution in potassium phosphate buffer $(0.1 \mathrm{M}, \mathrm{pH} 7.4)$ was monitored, which showed a peak at $\lambda_{\max }=472 \mathrm{~nm}$. Surprisingly, $\left[\mathbf{2 a}^{\bullet+}\right]\left[\mathrm{Cl}^{-}\right]$ showed high stability as less than $3 \%$ of the radical was decomposed over 7 days which corresponds to the half-life of $\sim 4000$ hours (Figure 4A and Figure S12A). In addition, even in the presence of excess sodium ascorbate in the buffer solution, [ $\left.\mathbf{2 a}^{\bullet+}\right]\left[\mathrm{Cl}^{-}\right]$ showed high stability showing the half-life of $\sim 3000$ hours (Figure S12B). Furthermore, $\left[2 \mathrm{a}^{\bullet+}\right]\left[\mathrm{Cl}^{-}\right]$survived in harsher conditions that most other organic radicals cannot (Figure 4B and Figure S13). For example, solution of $\left[2^{\circ}{ }^{*+}\right]\left[\mathrm{Cl}^{-}\right]$in horse blood serum showed ca. $2 \%$ decrease of UV-vis absorption over 500 minutes. $\left[2 \mathrm{a}^{\bullet+}\right]\left[\mathrm{Cl}^{-}\right]$also showed exceptional stability towards highly basic or oxidizing conditions as in $0.1 \mathrm{M}$ aqueous hydrogen peroxide or $0.1 \mathrm{M}$ aqueous sodium hydroxide, less than $2 \%$ of [ $\mathbf{2 a}^{\cdot+}$ ] $\left[\mathrm{Cl}^{-}\right.$] was decomposed over 500 minutes. In the presence of high excess $(0.5 \mathrm{M})$ thiophenol in dichloromethane solution, $25 \%$ decomposition of $\left[\mathbf{2 a}^{\bullet+}\right]\left[\mathrm{Cl}^{-}\right]$was observed after 500 minutes, while under $0.1 \mathrm{M}$ aqueous formic acid, $\sim 15 \%$ of $\left[2 \mathrm{a}^{\bullet+}\right]\left[\mathrm{Cl}^{-}\right]$was decomposed during 500 minutes. while. Notably, $\left[\mathbf{2 a}^{\bullet+}\right]\left[\mathrm{Cl}^{-}\right]$showed $\sim 2$ hours of half-life even in highly acidic $0.1 \mathrm{M}$ aqueous sulfuric acid solution.
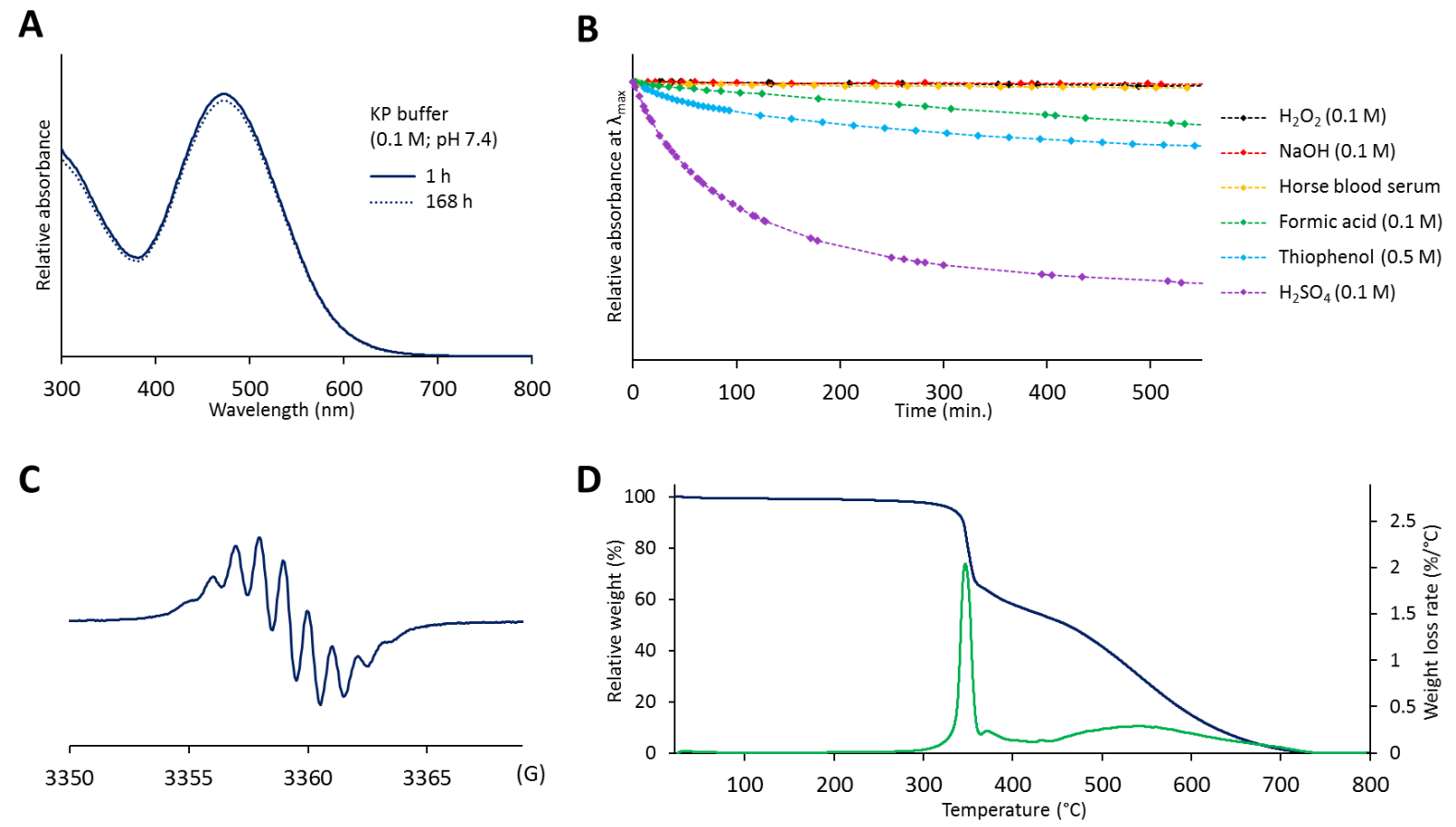

Figure 4. Stability of the 1,2-dicarbonyl radical.

(A) UV-vis spectra of $0.16 \mathrm{mM}\left[\mathbf{2 a}^{\bullet+}\right]\left[\mathrm{Cl}^{-}\right]$in potassium phosphate buffer $(0.1 \mathrm{M}, \mathrm{pH} 7.4) 1 \mathrm{~h}$ (solid line) and $168 \mathrm{~h}$ (dotted line) after dissolution. $\lambda_{\max }=472 \mathrm{~nm}$.

(B) Decay of $0.16 \mathrm{mM}\left[\mathbf{2 a}^{*+}\right]\left[\mathrm{Cl}^{-}\right]$in $0.1 \mathrm{M}$ aqueous hydrogen peroxide (black, $\lambda_{\max }=472 \mathrm{~nm}$ ), $0.1 \mathrm{M}$ aqueous sodium hydroxide (red, $\lambda_{\max }=472$ $\mathrm{nm}$ ), horse blood serum (yellow, $\lambda_{\max }=488 \mathrm{~nm}$, serum(70\%) mixed with distilled water(30\%)), $0.1 \mathrm{M}$ aqueous formic acid (green, $\lambda_{\max }=472$ $\mathrm{nm}$ ), $0.5 \mathrm{M}$ thiophenol in dichloromethane (blue, $\lambda_{\max }=521 \mathrm{~nm}$ ), and $0.1 \mathrm{M}$ aqueous sulfuric acid (purple, $\lambda_{\max }=472 \mathrm{~nm}$ ).

(C) EPR spectra of $\left[2 \mathrm{a}^{\circ+}\right][\mathrm{Cl}-]$ after heating for 6 hours at $200^{\circ} \mathrm{C}$.

(D) Thermal gravimetric analysis (dark blue) and differential thermal gravimetric (DTG) analysis (green) of [2a+ ${ }^{\circ+}\left[\mathrm{Cl}^{-}\right]$under air.

Thermal stability of $\left[2 \mathrm{a}^{\circ+}\right]\left[\mathrm{Cl}^{-}\right]$was also measured by heating the solid sample up to $200{ }^{\circ} \mathrm{C}$ over 6 hours, which showed no sign of decomposition, color change, or phase transition. The EPR spectrum of the heated $\left[2 \mathrm{a}^{\bullet+}\right]\left[\mathrm{Cl}^{-}\right]$was identical to the spectrum of freshly synthesized sample (Figure $\mathbf{4 C}$ ). Thermal gravimetric analysis (TGA) of $\left[\mathbf{2 a}^{\left.{ }^{*+}\right]}\left[\mathrm{Cl}^{-}\right]\right.$under air showed decomposition temperature of $c a .300^{\circ} \mathrm{C}$ (Figure 4D), which is among the highest decomposition temperature reported for organic radicals. ${ }^{3}$

Having highly stable and water soluble organic radical in hand, we considered the application of $\left[2 \mathrm{a}^{\circ+}\right]\left[\mathrm{Cl}^{-}\right]$as an organic radical contrast agent for magnetic resonance imaging. Magnetic resonance imaging (MRI) is one of the most used biomedical imaging techniques; ${ }^{16}$ however, toxicity of gadolinium based contrast agents restricts their use in some patients with impaired kidney performance. ${ }^{17}$ Therefore, stable and water soluble organic radicals have been investigated as non-toxic alternative MRI contrast agents. Up to date, sterically hindered aminoxyl radicals show significant potential due to their accessibility and 
functionalizability. ${ }^{18}$ Although aminoxyl radicals show reasonable stability toward water, they rapidly decompose to hydroxylamines under physiological conditions due to reducing agents such as ascorbate. ${ }^{19}$ For example, one of the most commonly used organic contrast agents, 3-carboxy-2,2,5,5-tetramethyl-1-pyrrolidinyloxy radical (3-CP) has a half-life of only 2 minutes in vivo. Relaxation performance of $\left[2^{-{ }^{*+}}\right]\left[\mathrm{Cl}^{-}\right]$was measured at the magnetic field of $7 \mathrm{~T}$ (Figure S18), which showed longitudinal $\left(r_{1}=0.14 \mathrm{mM}^{-1} \mathrm{~s}^{-1}\right)$ and transverse relaxivity $\left(r_{2}=0.58 \mathrm{mM}^{-1} \mathrm{~s}^{-1}\right)$ comparable to or higher than other organic molecule-based contrast agents (e.g. $r_{1}=0.15 \mathrm{mM}^{-1} \mathrm{~s}^{-1}, r_{2}=0.17 \mathrm{mM}^{-1} \mathrm{~s}^{-1}$ for $3-C P$ ). ${ }^{20}$

In summary, highly stable and water soluble 1,2 -dicarbonyl radicals $\mathbf{2} \mathbf{a}^{\mathbf{0}^{++}}$and $\mathbf{2} \mathbf{b}^{\mathbf{}}{ }^{++}$were synthesized and fully characterized. $\mathrm{X}$ ray crystallography, EPR spectroscopy, and DFT calculation suggest the unpaired electron is located on the central $\mathrm{C}_{2} \mathrm{O}_{2}$ unit, which is a rare example of NHC-derived radicals with minimal delocalization of spin density over the NHC fragments. In addition, $\mathbf{2} \mathbf{a}^{\bullet+}$ and $\mathbf{2} \mathbf{b}^{\bullet+}$ showed high stability towards various chemical and physiological conditions. Interestingly, similar longitudinal relaxivity and higher transverse relaxivity was observed compared to the previously reported organic molecule-based contrast agents which makes these radicals promising candidates for organic radical MRI contrast agents.

\section{Acknowledgements}

This work was supported by the National Supercomputing Center with supercomputing resources including technical support (KSC-2019-CRE-0162), and by the National Research Foundation of Korea (NRF-2019R1A2C2010732). X-ray diffraction experiment with synchrotron radiation was performed at the Pohang Accelerator Laboratory (Beamline 2D). High resolution mass spectrometry was performed at the Korea Basic Science Institute (DS107). We thank Dr. Younghoon Kim for assistance with TGA analysis, and Dr. Ewa Pietrasiak and Dr. Dmitry V. Yandulov for helpful discussions.

\section{Author contributions}

Y. K. designed and synthesized the 1,2-dicarbonyl radicals, performed experiments and characterization, and wrote the

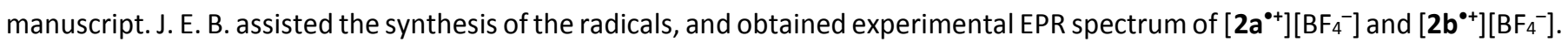
G. Y. J. measured the stability of $\left[2 a^{\bullet+}\right]\left[\mathrm{Cl}^{-}\right]$in the buffer solutions. S. S. K. assisted the NMR relaxation experiments. H. S. measured the cyclic voltammograms. E. L. directed the project.

\section{Notes}

The authors declare the following competing financial interest: A patent application has been led through POSTECH on methods and reagents presented in this manuscript.

\section{References}

(1) Gomberg, M. An Instance of Trivalent Carbon: Triphenylmethyl. J. Am. Chem. Soc. 1900, 22, 757-771.

(2) (a) Forrester, A. R.; Thomson, R. H. Stable Nitroxide Radicals. Nature 1964, 203, 74-75. (b) Back, O.; Celik, M. A.; Frenking, G.; Melaimi, M.; Donnadieu, B.; Bertrand, G. A crystalline phosphinyl radical cation. J. Am. Chem. Soc. 2010, 132, 10262-10263.

(3) Hicks, R. G., Stable Radicals: Fundamentals and Applied Aspects of Odd-Electron Compounds. John Wiley \& Sons, Ltd: 2010.

(4) (a) Xia, S.; Villamena, F. A.; Hadad, C. M.; Kuppusamy, P.; Li, Y.; Zhu, H.; Zweier, J. L. Reactivity of molecular oxygen with ethoxycarbonyl derivatives of tetrathiatriarylmethyl radicals. J. Org. Chem. 2006, 71, 7268-7279. (b) Frank, J.; Elewa, M.; Said, M. M.; El Shihawy, H. A.; ElSadek, M.; Muller, D.; Meister, A.; Hause, G.; Drescher, S.; Metz, H.; Imming, P.; Mader, K. Synthesis, Characterization, and Nanoencapsulation of Tetrathiatriarylmethyl and Tetrachlorotriarylmethyl (Trityl) Radical Derivatives-A Study To Advance Their Applicability as in Vivo EPR Oxygen Sensors. J. Org. Chem. 2015, 80, 6754-6766. (c) Hintz, H.; Vanas, A.; Klose, D.; Jeschke, G.; Godt, A. Trityl Radicals with a Combination of the Orthogonal Functional Groups Ethyne and Carboxyl: Synthesis without a Statistical Step and EPR Characterization. J. Org. Chem. 2019, 84, 3304-3320.

(5) (a) Tomioka, H.; Iwamoto, E.; Itakura, H.; Hirai, K. Generation and characterization of a fairly stable triplet carbene. Nature 2001, 412, 626628. (b) Tang, B.; Zhao, J.; Xu, J.-F.; Zhang, X. Tuning the stability of organic radicals: from covalent approaches to non-covalent approaches. Chem. Sci. 2020, 11, 1192-1204.

(6) Russell, G. A.; Strom, E. T.; Talaty, E. R.; Weiner, S. A. Semidiones. I. Acyclic Semidione Radical Anions and Cations Containing a Single Aryl Substituent1. J. Am. Chem. Soc. 1966, 88, 1998-2004.

(7) (a) Zanello, P.; Corsini, M. Homoleptic, mononuclear transition metal complexes of 1,2-dioxolenes: Updating their electrochemical-tostructural (X-ray) properties. Coord. Chem. Rev. 2006, 250, 2000-2022. (b) Kirk, M. L.; Shultz, D. A. Transition metal complexes of donoracceptor biradicals. Coord. Chem. Rev. 2013, 257, 218-233.

(8) (a) Hopkinson, M. N.; Richter, C.; Schedler, M.; Glorius, F. An overview of N-heterocyclic carbenes. Nature 2014, 510, 485-496. (b) Bourissou, D.; Guerret, O.; Gabbaï, F. P.; Bertrand, G. Stable Carbenes. Chem. Rev. 2000, 100, 39-92. (c) Igau, A.; Grutzmacher, H.; Baceiredo, A.; Bertrand, G. Analogous $\alpha, \alpha^{\prime}$-bis-carbenoid, triply bonded species: synthesis of a stable $\lambda 3$-phosphino carbene- $\lambda 5$-phosphaacetylene. J. Am. Chem. Soc. 1988, 110, 6463-6466. (d) Arduengo, A. J.; Harlow, R. L.; Kline, M. A stable crystalline carbene. J. Am. Chem. Soc. 1991, 113, 361-363. (e) Lavallo, V.; Canac, Y.; Prasang, C.; Donnadieu, B.; Bertrand, G. Stable cyclic (alkyl)(amino)carbenes as rigid or flexible, bulky, 
electron-rich ligands for transition-metal catalysts: a quaternary carbon atom makes the difference. Angew. Chem. Int. Ed. 2005, 44, 57055709. (f) Melaimi, M.; Soleilhavoup, M.; Bertrand, G. Stable Cyclic Carbenes and Related Species beyond Diaminocarbenes. Angew. Chem. Int. Ed. 2010, 49, 8810-8849.

(9) (a) Wang, Y.; Robinson, G. H. Carbene-stabilized main group diatomic allotropes. Dalton Trans. 2012, 41, 337-345. (b) Chandra Mondal, K.; Roy, S.; Roesky, H. W. Silicon based radicals, radical ions, diradicals and diradicaloids. Chem. Soc. Rev. 2016, 45, 1080-1111. (c) Yao, S.; Xiong, Y.; Driess, M. A New Area in Main-Group Chemistry: Zerovalent Monoatomic Silicon Compounds and Their Analogues. Acc. Chem. Res. 2017, 50, 2026-2037.

(10) Martin, C. D.; Soleilhavoup, M.; Bertrand, G. Carbene-Stabilized Main Group Radicals and Radical lons. Chem. Sci. 2013, 4, $3020-3030$.

(11) (a) Mahoney, J. K.; Martin, D.; Moore, C. E.; Rheingold, A. L.; Bertrand, G. Bottleable (amino)(carboxy) radicals derived from cyclic (alkyl)(amino) carbenes. J. Am. Chem. Soc. 2013, 135, 18766-18769. (b) Martin, D.; Moore, C. E.; Rheingold, A. L.; Bertrand, G. An air-stable oxyallyl radical cation. Angew. Chem. Int. Ed. 2013, 52, 7014-7017. (c) Mahoney, J. K.; Martin, D.; Thomas, F.; Moore, C. E.; Rheingold, A. L.; Bertrand, G. Air-persistent monomeric (amino)(carboxy) radicals derived from cyclic (alkyl)(amino) carbenes. J. Am. Chem. Soc. 2015, 137, 7519-7525. (d) Deardorff, C. L.; Eric Sikma, R.; Rhodes, C. P.; Hudnall, T. W. Carbene-derived alpha-acyl formamidinium cations: organic molecules with readily tunable multiple redox processes. Chem. Commun. 2016, 52, 9024-9027. (e) Regnier, V.; Molton, F.; Philouze, C.; Martin, D. An air-persistent oxyallyl radical cation with simple di(methyl)amino substituents. Chem. Commun. 2016, 52, 1142211425. (f) Mahoney, J. K.; Jazzar, R.; Royal, G.; Martin, D.; Bertrand, G. The Advantages of Cyclic Over Acyclic Carbenes To Access Isolable Capto-Dative C-Centered Radicals. Chem. Eur. J. 2017, 23, 6206-6212.

(12) (a) Hansmann, M. M.; Melaimi, M.; Bertrand, G. Crystalline Monomeric Allenyl/Propargyl Radical. J. Am. Chem. Soc. 2017, 139, 1562015623. (b) Li, Y.; Mondal, K. C.; Samuel, P. P.; Zhu, H.; Orben, C. M.; Panneerselvam, S.; Dittrich, B.; Schwederski, B.; Kaim, W.; Mondal, T.; Koley, D.; Roesky, H. W. C4 cumulene and the corresponding air-stable radical cation and dication. Angew. Chem. Int. Ed. 2014, 53, 41684172. (c) Jin, L.; Melaimi, M.; Liu, L.; Bertrand, G. Singlet carbenes as mimics for transition metals: synthesis of an air stable organic mixed valence compound [M2(C2)+; M = cyclic(alkyl)(amino)carbene]. Org. Chem. Front. 2014, 1, 351-354. (d) Hansmann, M. M.; Melaimi, M.; Bertrand, G. Organic Mixed Valence Compounds Derived from Cyclic (Alkyl)(amino)carbenes. J. Am. Chem. Soc. 2018, 140, 2206-2213. (e) Hansmann, M. M.; Melaimi, M.; Munz, D.; Bertrand, G. Modular Approach to Kekule Diradicaloids Derived from Cyclic (Alkyl)(amino)carbenes. J. Am. Chem. Soc. 2018, 140, 2546-2554.

(13) (a) Eymann, L. Y. M.; Tskhovrebov, A. G.; Sienkiewicz, A.; Bila, J. L.; Zivkovic, I.; Ronnow, H. M.; Wodrich, M. D.; Vannay, L.; Corminboeuf, C.; Pattison, P.; Solari, E.; Scopelliti, R.; Severin, K. Neutral Aminyl Radicals Derived from Azoimidazolium Dyes. J. Am. Chem. Soc. 2016, 138, 15126-15129. (b) Back, J.; Park, J.; Kim, Y.; Kang, H.; Kim, Y.; Park, M. J.; Kim, K.; Lee, E. Triazenyl Radicals Stabilized by N-Heterocyclic Carbenes. J. Am. Chem. Soc. 2017, 139, 15300-15303.

(14) (a) Ueng, S. H.; Solovyev, A.; Yuan, X.; Geib, S. J.; Fensterbank, L.; Lacote, E.; Malacria, M.; Newcomb, M.; Walton, J. C.; Curran, D. P. Nheterocyclic carbene boryl radicals: a new class of boron-centered radical. J. Am. Chem. Soc. 2009, 131, 11256-11262. (b) Tanaka, H.; Ichinohe, M.; Sekiguchi, A. An isolable NHC-stabilized silylene radical cation: synthesis and structural characterization. J. Am. Chem. Soc. 2012, 134, 5540-5543. (c) Matsumoto, T.; Gabbaï, F. P. A Borenium Cation Stabilized by an N-Heterocyclic Carbene Ligand. Organometallics 2009, 28, 4252-4253. (d) Bissinger, P.; Braunschweig, H.; Damme, A.; Krummenacher, I.; Phukan, A. K.; Radacki, K.; Sugawara, S. Isolation of a neutral boron-containing radical stabilized by a cyclic (alkyl)(amino)carbene. Angew. Chem. Int. Ed. 2014, 53, 7360-7363. (e) Park, J.; Song, H.; Kim, Y.; Eun, B.; Kim, Y.; Bae, D. Y.; Park, S.; Rhee, Y. M.; Kim, W. J.; Kim, K.; Lee, E. N-heterocyclic carbene nitric oxide radicals. J. Am. Chem. Soc. 2015, 137, 4642-4645. (f) Abraham, M. Y.; Wang, Y.; Xie, Y.; Gilliard, R. J., Jr.; Wei, P.; Vaccaro, B. J.; Johnson, M. K.; Schaefer, H. F., 3rd; Schleyer, P. V.; Robinson, G. H. Oxidation of carbene-stabilized diarsenic: diarsene dications and diarsenic radical cations. J. Am. Chem. Soc. 2013, 135, 2486-2488. (g) Park, J. S.; Karnas, E.; Ohkubo, K.; Chen, P.; Kadish, K. M.; Fukuzumi, S.; Bielawski, C. W.; Hudnall, T. W.; Lynch, V. M.; Sessler, J. L. Ion-mediated electron transfer in a supramolecular donor-acceptor ensemble. Science 2010, 329, $1324-1327$. (h) Silva Valverde, M. F.; Schweyen, P.; Gisinger, D.; Bannenberg, T.; Freytag, M.; Kleeberg, C.; Tamm, M. N-Heterocyclic Carbene Stabilized Boryl Radicals. Angew. Chem. Int. Ed. 2017, 56, 1135-1140. (i) Kim, Y.; Kim, K.; Lee, E. Oxime Ether Radical Cations Stabilized by NHeterocyclic Carbenes. Angew. Chem. Int. Ed. 2018, 57, 262-265. (j) Li, B.; Kundu, S.; Stuckl, A. C.; Zhu, H.; Keil, H.; Herbst-Irmer, R.; Stalke, D.; Schwederski, B.; Kaim, W.; Andrada, D. M.; Frenking, G.; Roesky, H. W. A Stable Neutral Radical in the Coordination Sphere of Aluminum. Angew. Chem. Int. Ed. 2017, 56, 397-400. (k) Kim, Y.; Lee, E. An air-stable N-heterocyclic carbene iminoxyl borate radical zwitterion. Chem. Commun. 2018, 54, 6824-6827. (I) Sharma, M. K.; Blomeyer, S.; Glodde, T.; Neumann, B.; Stammler, H.-G.; Hinz, A.; van Gastel, M.; Ghadwal, R. S. Isolation of singlet carbene derived 2-phospha-1,3-butadienes and their sequential one-electron oxidation to radical cations and dications. Chem. Sci. 2020, 11, 1975-1984. (m) Styra, S.; Melaimi, M.; Moore, C. E.; Rheingold, A. L.; Augenstein, T.; Breher, F.; Bertrand, G. Crystalline Cyclic (Alkyl)(amino)carbene-tetrafluoropyridyl Radical. Chem. Eur. J. 2015, 21, 8441-8446. (n) Rottschafer, D.; Neumann, B.; Stammler, H. G.; van Gastel, M.; Andrada, D. M.; Ghadwal, R. S. Crystalline Radicals Derived from Classical N-Heterocyclic Carbenes. Angew. Chem. Int. Ed. 2018, 57, 4765-4768.

(15) Kim, Y.; Lee, E. Stable Organic Radicals Derived from N-Heterocyclic Carbenes. Chem. Eur. J. 2018, 24, 19110-19121.

(16) (a) Terreno, E.; Castelli, D. D.; Viale, A.; Aime, S. Challenges for molecular magnetic resonance imaging. Chem. Rev. 2010, 110, $3019-3042$. (b) Caravan, P.; Ellison, J. J.; McMurry, T. J.; Lauffer, R. B. Gadolinium(III) Chelates as MRI Contrast Agents: Structure, Dynamics, and Applications. Chem. Rev. 1999, 99, 2293-2352.

(17) Olchowy, C.; Cebulski, K.; Lasecki, M.; Chaber, R.; Olchowy, A.; Kalwak, K.; Zaleska-Dorobisz, U. The presence of the gadolinium-based contrast agent depositions in the brain and symptoms of gadolinium neurotoxicity - A systematic review. PLoS One 2017, 12, e0171704.

(18) (a) Janzen, E. G.; Towner, R. A., Aminoxyl Radicals as MRI Contrast Agents. In Bioactive Spin Labels, Zhdanov, R. I., Ed. Springer Berlin Heidelberg: Berlin, Heidelberg, 1992; pp 573-583. (b) Sowers, M. A.; McCombs, J. R.; Wang, Y.; Paletta, J. T.; Morton, S. W.; Dreaden, E. C.; Boska, M. D.; Ottaviani, M. F.; Hammond, P. T.; Rajca, A.; Johnson, J. A. Redox-responsive branched-bottlebrush polymers for in vivo MRI and fluorescence imaging. Nat Commun 2014, 5, 5460.

(19) (a) Paletta, J. T.; Pink, M.; Foley, B.; Rajca, S.; Rajca, A. Synthesis and reduction kinetics of sterically shielded pyrrolidine nitroxides. Org. Lett. 2012, 14, 5322-5325. (b) Hyodo, F.; Matsumoto, K.; Matsumoto, A.; Mitchell, J. B.; Krishna, M. C. Probing the intracellular redox status of tumors with magnetic resonance imaging and redox-sensitive contrast agents. Cancer Res. 2006, 66, 9921-9928. 
(20) (a) Rajca, A.; Wang, Y.; Boska, M.; Paletta, J. T.; Olankitwanit, A.; Swanson, M. A.; Mitchell, D. G.; Eaton, S. S.; Eaton, G. R.; Rajca, S. Organic radical contrast agents for magnetic resonance imaging. J. Am. Chem. Soc. 2012, 134, 15724-15727. (b) Nguyen, H. V.; Chen, Q.; Paletta, J. T.; Harvey, P.; Jiang, Y.; Zhang, H.; Boska, M. D.; Ottaviani, M. F.; Jasanoff, A.; Rajca, A.; Johnson, J. A. Nitroxide-Based Macromolecular Contrast Agents with Unprecedented Transverse Relaxivity and Stability for Magnetic Resonance Imaging of Tumors. ACS Cent. Sci. 2017, $3,800-811$. 